\title{
Article
}

\section{Health Risks of Sarcopenic Obesity in Overweight Children and Adolescents: Data from the CHILT III Programme (Cologne)}

\author{
Carolin Sack ${ }^{1, *}$, Nina Ferrari ${ }^{1,2}$, David Friesen ${ }^{1}$, Fabiola Haas ${ }^{1}$, Marlen Klaudius ${ }^{1}$, Lisa Schmidt ${ }^{1}$, \\ Gabriel Torbahn ${ }^{3} \mathbb{D}$, Hagen Wulff ${ }^{4}$ and Christine Joisten ${ }^{1}(\mathbb{D}$
}

check for updates

Citation: Sack, C.; Ferrari, N.; Friesen,

D.; Haas, F.; Klaudius, M.; Schmidt,

L.; Torbahn, G.; Wulff, H.; Joisten, C.

Health Risks of Sarcopenic Obesity in

Overweight Children and

Adolescents: Data from the CHILT III

Programme (Cologne). J. Clin. Med.

2022, 11, 277. https://doi.org/

$10.3390 / j \mathrm{~cm} 11010277$

Academic Editor: Patrick De Boever

Received: 4 December 2021

Accepted: 4 January 2022

Published: 5 January 2022

Publisher's Note: MDPI stays neutral with regard to jurisdictional claims in published maps and institutional affiliations.

Copyright: (c) 2022 by the authors. Licensee MDPI, Basel, Switzerland. This article is an open access article distributed under the terms and conditions of the Creative Commons Attribution (CC BY) license (https:/ / creativecommons.org/licenses/by/ $4.0 /)$.
1 Department for Physical Activity in Public Health, Institute of Movement and Neurosciences, Am Sportpark Müngersdorf 6, German Sport University Cologne, 50933 Cologne, Germany; nina.ferrari@uk-koeln.de (N.F.); d.friesen@dshs-koeln.de (D.F.); f.haas@dshs-koeln.de (F.H.); m.klaudius@dshs-koeln.de (M.K.); ernaehrungschmidt@gmail.com (L.S.); c.joisten@dshs-koeln.de (C.J.)

2 Cologne Center for Prevention in Childhood and Youth/Heart Center Cologne, University Hospital of Cologne, Kerpener Str. 62, 50937 Cologne, Germany

3 Department of Pediatrics, Paracelsus Medical University, Breslauer Str. 201, 90471 Nuremberg, Germany; gabriel.torbahn@klinikum-nuernberg.de

4 Department of Sport and Health Sciences, Faculty of Human Sciences, University of Potsdam, Karl-Liebknecht-Str. 24-25, 14476 Potsdam, Germany; hagen.wulff@uni-potsdam.de

* Correspondence: csack@smail.uni-koeln.de

\begin{abstract}
Sarcopenic obesity is increasingly found in youth, but its health consequences remain unclear. Therefore, we studied the prevalence of sarcopenia and its association with cardiometabolic risk factors as well as muscular and cardiorespiratory fitness using data from the German Children's Health InterventionaL Trial (CHILT III) programme. In addition to anthropometric data and blood pressure, muscle and fat mass were determined with bioelectrical impedance analysis. Sarcopenia was classified via muscle-to-fat ratio. A fasting blood sample was taken, muscular fitness was determined using the standing long jump, and cardiorespiratory fitness was determined using bicycle ergometry. Of the 119 obese participants included in the analysis ( $47.1 \%$ female, mean age 12.2 years), 83 (69.7\%) had sarcopenia. Affected individuals had higher gamma-glutamyl transferase, higher glutamate pyruvate transaminase, higher high-sensitivity C-reactive protein, higher diastolic blood pressure, and lower muscular and cardiorespiratory fitness (each $p<0.05$ ) compared to participants who were 'only' obese. No differences were found in other parameters. In our study, sarcopenic obesity was associated with various disorders in children and adolescents. However, the clinical value must be tested with larger samples and reference populations to develop a unique definition and appropriate methods in terms of identification but also related preventive or therapeutic approaches.
\end{abstract}

Keywords: sarcopenia; sarcopenic obesity; muscle-to-fat ratio; juvenile obesity

\section{Introduction}

Obesity in children and adolescents is a growing health problem [1]. Between 1975 and 2016, the global prevalence of overweight in children and adolescents worldwide increased from $0.7 \%$ to $5.6 \%$ in girls and $0.9 \%$ to $7.8 \%$ in boys [2]. In Germany, the prevalence of overweight including obesity was $15.4 \%$ among children aged 3-17 years based on the Child and Adolescent Health Survey (KiGGS, wave 2 2014-2017) [1]. The current COVID-19 pandemic is expected to lead to a further increase [3].

In addition to the possible persistence of overweight and obesity into adulthood, along with its corresponding health consequences [4], the significantly increased risk of cardiometabolic, orthopaedic, and psychological comorbidities is problematic even in this young age group [5,6]. Children and adolescents with overweight and obesity are more likely to have cardiovascular risk factors such as high blood pressure, lipid metabolism 
disorders, and glucose metabolism disorders. This may lead to the development of noncommunicable diseases such as type 2 diabetes mellitus [1,7,8], endothelial dysfunction, non-alcoholic fatty liver disease (NAFLD), and musculoskeletal dysfunction $[1,6,9]$. The complete picture of the metabolic syndrome (MetS) is found in $6 \%$ to $39 \%$ of overweight children, depending on the underlying definition [10]. Visceral fat content, the associated secretion of so-called adipocytokines [11], and the presence of low-threshold systemic inflammation play a central role in the development of the above-mentioned comorbidities [12]. In addition, an inverse relationship between cardiometabolic risk factors and low or disproportionate (with respect to body fat) muscle mass is increasingly being described in adulthood as expression of the so-called sarcopenic obesity [13-15]. Classically, sarcopenia is associated with underweight due to the loss of muscle mass as well as reduced muscle strength and function. The European Working Group on Sarcopenia in Older People (EWGSOP) expanded the definition of sarcopenia to include both primary sarcopeniacharacterised by reduced muscle mass, limited muscle function, and strength at an older age and secondary sarcopenia in the context of chronic diseases, including obesity [16]. However, people with sarcopenic obesity can be of normal weight or 'only' overweight, but their relatively low muscle mass may be masked by a higher fat mass $[14,15,17]$. Thus, in addition to measuring handgrip strength, the muscle-to-fat ratio (MFR) is used to determine the severity of sarcopenic obesity [17-19]. MFR is an indicator for cardiometabolic risk factors and metabolic syndrome in adults, while it correlates negatively with waist circumference, systolic blood pressure, and blood lipid levels [19]. Additionally, MFR can also be used to assess cardiometabolic health in children [20].

Despite these initial indications, few studies to date have examined the presence of sarcopenic obesity in childhood and adolescence or possible concomitant diseases [17,18]. In order to avoid the negative health consequences of sarcopenic obesity, adequate knowledge and evidence-informed countermeasures are urgently needed. Therefore, we investigated the correlations between the presence of cardiometabolic risk factors and the occurrence of sarcopenia/sarcopenic obesity using the Children's Health Interventional Trial (CHILT III) programme, which is an outpatient weight management programme for obese children and their families.

\section{Materials and Methods}

\subsection{Sample Description}

In this study, the input data of the CHILT III programme of the German Sport University Cologne from the years 2003-2021 were used, which is a family-based, multimodal, outpatient programme for obese children and adolescents aged between 8 and 16 years [21].

Of 538 subjects, 119 (47.1\% female) could be included in the analysis, as it was possible to classify sarcopenia by MFR followed by Kim et al. [22]. The MFR cut-off values were defined according to McCarthy et al. [20] (cut-off = mean value -2 SD of the MFR of the middle fifth of the BMI range). Based on this, the MFR cut-off value for sarcopenia is at 1.25 for boys of all ages, 1.1 for girls between $5-10$ years, and 0.8 for girls between 10-18 years [20]. Accordingly, the diagnosis of sarcopenia was made when the MFR was below these cut-off values. Therefore, in 83 children (69.7\%), sarcopenia was present according to the above criteria (see Figure 1). None of them suffered from an overt diabetes mellitus type I or II.

\subsubsection{Anthropometric Data}

The height of the children and adolescents was measured barefoot in cm; weight was measured in kg. A calibrated scale and a stadiometer were used for this purpose [23]. BMI was divided into percentiles according to Kromeyer-Hauschild et al. [24]. Following the guidelines of the 'Arbeitsgemeinschaft für Adipositas (AGA)', a BMI above the 90th percentile was classified as overweight and a BMI above the 97th percentile was classified 
as obese [25]. In addition, the BMI standard deviation score (SDS) was calculated using the least mean squares (LMS) method for non-normally distributed characteristics [25]:

$$
\mathrm{SDS}_{\mathrm{LMS}}=\frac{[\mathrm{BMI} / \mathrm{M}[\mathrm{t}]]^{\mathrm{L}[\mathrm{t}]}-1}{\mathrm{~L}[\mathrm{t}] \mathrm{S}[\mathrm{t}]}
$$

$M[t], L[t]$, and $S[t]$ are parameters for the participants' age and sex.

\section{Total number of children in CHILT III} $n=538$

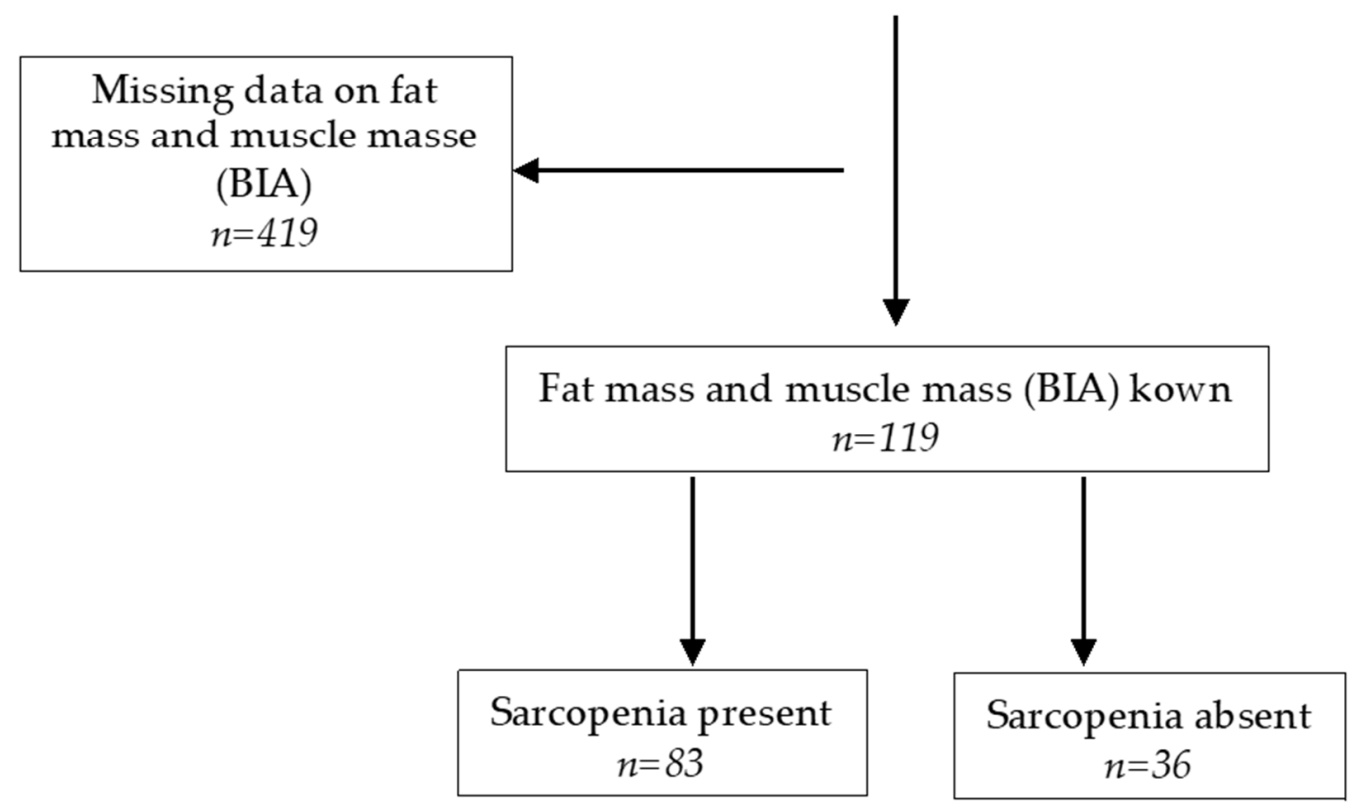

Figure 1. Flowchart of the selected subjects.

Waist circumference was measured in $\mathrm{cm}$ using a standard tape measure. The measurement was taken midway between the anterior superior iliac spine and the lowest rib with the participant standing upright. Using a body fat caliper (Harpender Skinfold Caliper HSK-BI, British Indicators, West Sussex, UK), skinfold thickness was measured in triplicate to the nearest $0.2 \mathrm{~mm}$ in triceps and subscapular according to a standardised protocol [26], and the mean of the three results was reported. Sex- and age-specific equations were used to calculate body fat percentage, as in similar studies [27-29].

\subsubsection{Bioelectrical Impedance Analysis}

Fat mass and muscle mass were determined by bioelectrical impedance analysis (BIA; Nutriguard-MS, Data Input GmbH, Pöcking, Germany). This was determined to $0.1 \mathrm{~kg}$ and $0.1 \%$ with the four-point measurement. The frequency of the measurement was $50 \mathrm{kHz}$ [30]. The following values were determined from the measurement: resistance $\left({ }^{\circledR}\right)$, reactance $\left(\mathrm{Xc}_{\mathrm{c}}\right)$, checksum $(\Sigma)$, total resistance (Rtot.), and phase angle $(\varphi)$. Using the NutriPlus software (NutriPlus, Data Input GmbH, Pöcking, Germany), fat and muscle mass in kg were calculated from these values and reported [31].

\subsubsection{Skeletal Muscle Mass, Fat Mass, and Muscle-to-Fat Ratio}

In addition, skeletal muscle mass (SMM) was calculated according to Janssen et al. [32]:

$$
\left.\operatorname{SMM}(\mathrm{kg})=\left[\mathrm{Ht}^{2} / \mathrm{R} \times 0.401\right)+(\operatorname{sex} \times 3.825)+(\operatorname{age} \times-0.071)\right]+5.102
$$

( $\mathrm{Ht}=$ height in $\mathrm{cm}, \mathrm{R}=\mathrm{BIA}-$ resistance in $\Omega$, sex $=1=$ male, $0=$ female, age in years $)$. 
This formula assumes a strong correlation between SMM as calculated by MRI and BIA resistance [32]. Furthermore, the skeletal muscle index $(\mathrm{SMI})$ in \% (SMM/body mass $\times 100)$ was calculated [33].

The SMI was also calculated according to Park et al. [13]:

$$
\text { SMI }\left(\mathrm{kg} / \mathrm{m}^{2}\right)=\operatorname{SMM}(\mathrm{kg}) / \text { body size }\left(\mathrm{m}^{2}\right) \text {. }
$$

The MFR was calculated according to McCarthy et al. [20]:

$$
\text { MFR }=\text { SMM in } \mathrm{kg} / \text { body fat mass }(\mathrm{FM}) \text { in } \mathrm{kg} \text {. }
$$

For the calculation of the MFR, in this study, skeletal muscle mass and fat mass were given and used by the NutriPlus software of BIA measurements [31].

\subsubsection{Blood Pressure}

Blood pressure was measured oscillometrically three times using an automatic blood pressure monitor after approximately 5-10 min of rest [23]. The cuff size was chosen so that two-thirds of the upper arm length was covered. The mean value from all three calculations was calculated and documented. We classified hypertension according to the S2k guideline of the German Society for Paediatric Cardiology using age- and height-specific reference values [34].

\subsubsection{Laboratory Parameters}

Blood values were taken after fasting (12 $\mathrm{h}$ food and drink abstinence, including plain water, no teeth brushing) and analysed in the laboratory of the German Sport University. Fasting blood glucose, total cholesterol, high-density lipoprotein (HDL), and triglycerides were measured directly. Low-density lipoprotein (LDL) cholesterol was determined indirectly from total cholesterol, HDL, and triglycerides using the Friedewald equation [35]. Insulin was determined using human insulin standards (Elecsys Insulin) from Roche Diagnostics, Mannheim [36]. The homeostatic model assessment (HOMA index) was used as a parameter of insulin sensitivity and was calculated by the following formula [23,37]:

$$
\mathrm{HOMA}=(\text { insulin }[\mathrm{mU} / \mathrm{L}] \times \text { glucose }[\mathrm{mmol} / \mathrm{L}]) / 22.5 \text {. }
$$

In addition, GGT (in U/L) was determined by a kinetic photometric assay using reagents from ABX Pentra (HORIBA ABX 2007). GPT and GOT (each in U/L) were determined via an optimised UV assay without pyridoxal phosphate using reagents from ABX Pentra (HORIBA ABX 2005/2007) [36]. High-sensitivity (hs) CRP (in mg/L) was determined using the cobas c system by Roche/Hitachi. Leptin was measured by a direct sandwich enzyme-linked immunosorbent assay (ELISA, kit from MERCK/Millipore KgaA, Darmstadt, Germany).

\subsubsection{Definition of Metabolic Syndrome (MetS)}

The metabolic syndrome was defined according to the International Diabetes Federation (IDF) classification modified for children and adolescents up to 16 years [38]. For adolescents over 16 years, we applied the IDF criteria for adults [39] (see Appendix A Table A1).

\subsubsection{Cardiorespiratory Fitness/Ergometry}

Maximum cardiorespiratory performance capacity (in watts) was determined by bicycle ergometry (Ergometrics er900, Ergoline, Bitz, Germany). The children started at 25 watts, and workload was increased by 25 every 2 min until the maximum load was reached. The children were encouraged to continue until they had reached their maximum physical capacity. Relative watts (watts $/ \mathrm{kg}$ ) was defined as the maximum watts in relation to body weight [21]. 
Children with acute illnesses, such as febrile infections, asthma attacks, or metabolic diseases were excluded from ergometry. Other contraindications include cardiomyopathies, certain vascular anomalies, and heart failure [40].

\subsubsection{Muscular Fitness/Standing Long Jump}

The standing long jump was used to measure muscular fitness, resp. jumping strength, and associated leg muscle strength. This test was based on the Dordel-Koch test with defined standard values. In the test, the children and adolescents had to jump as far as possible using both legs without a run-up. The children made two attempts, and the better one was scored [41].

\subsection{Statistical Analysis}

The data were analysed using IBM SPSS Statistics, version 28.0; descriptive statistics were presented as means and standard deviations (SD). Normal distribution of the parameters was checked using the Kolmogorov-Smirnov test. Parameters with normal distribution were examined with parametric tests. Parameters that were not normally distributed were tested using the Mann-Whitney U-test. A $t$-test was used to compare the means of continuous parameters with variance homogeneity. In the case of variance heterogeneity, the T-test with Welch correction was used. We tested categorical parameters using a Chi-squared test. Statistical significance was defined as a $p$-value $<0.05$.

\section{Results}

\subsection{Anthropometry}

Table 1 shows the anthropometric data of the total sample, as well as the possible differences between participants with and without sarcopenia based on the above-mentioned cut-offs. Of the children with sarcopenia $(n=83), 69.9 \%$ were male and $30.1 \%$ were female; in the group without sarcopenia, $(n=36), 13.9 \%$ were male and $86.1 \%$ were female $(p<0.001)$. On average, children and adolescents with and without sarcopenia were the same age, height, and weight (see Table 1). However, there were significant differences in BMI-SDS $(p=0.018)$ and waist circumference $(p=0.024)$.

Table 1. Anthropometric data for the whole group and by the presence of sarcopenia.

\begin{tabular}{ccccc}
\hline Parameter & Total & Sarcopenia Absent & Sarcopenia Present & $p$-Value \\
\hline Age (years) & $12.2 \pm 2.2(n=119)$ & $12.4 \pm 1.9(n=36)$ & $12.2 \pm 2.3(n=83)$ & $p=0.635^{\dagger}$ \\
\hline Height $(\mathrm{m})$ & $1.57 \pm 0.12(n=118)$ & $1.58 \pm 0.08(n=35)$ & $1.57 \pm 0.14(n=83)$ & $p=0.623^{\dagger}$ \\
\hline Weight $(\mathrm{kg})$ & $76.6 \pm 22.8(n=118)$ & $73.0 \pm 16.7(n=35)$ & $78.1 \pm 24.9(n=83)$ & $p=0.469 \ddagger$ \\
\hline BMI $\left(\mathrm{kg} / \mathrm{m}^{2}\right)$ & $30.4 \pm 5.6(n=118)$ & $29.0 \pm 4.3(n=35)$ & $31.0 \pm 6.0(n=83)$ & $p=0.083^{\ddagger}$ \\
\hline BMI-SDS & $2.52 \pm 0.48(n=118)$ & $2.36 \pm 0.44(n=35)$ & $2.58 \pm 0.48(n=83)$ & $p=0.018^{\dagger *}$ \\
\hline Waist circumference $(\mathrm{cm})$ & $96.2 \pm 14.8(n=117)$ & $91.1 \pm 11.2(n=35)$ & $98.3 \pm 15.6(n=82)$ & $p=0.024^{\ddagger *}$ \\
\hline
\end{tabular}

Data are presented as mean \pm SD ( $n=$ number $)$. Abbreviations: BMI = body mass index; SDS = standard deviation score. ${ }^{\dagger} t$-test for presence of sarcopenia, ${ }^{\ddagger}$ Mann-Whitney U-test, ${ }^{*}$ statistical significance.

In children with sarcopenia, boys had a higher waist circumference $(p=0.042)$, higher GPT $(p=0.006)$, higher skeletal muscle mass, and higher SMI $(p<0.001)$, as well as a higher $\operatorname{MFR}(p=0.026)$ than girls (see Appendix A Tables A2-A4).

\subsection{Laboratory Parameters and Blood Pressure}

Children with sarcopenia showed a significantly higher GGT $(p=0.028)$, higher GPT $(p=0.003)$, a significantly higher hs-CRP $(p=0.009)$, and significantly higher diastolic blood pressure $(p=0.046)$. The other parameters did not differ significantly among participants with and without sarcopenia (see Table 2). 
Table 2. Blood pressure and laboratory parameters of the whole group and by the presence of sarcopenia.

\begin{tabular}{ccccc}
\hline Parameter & Total & Sarcopenia Absent & Sarcopenia Present & $p$-Value \\
\hline Systolic blood pressure $(\mathrm{mmHg})$ & $115.2 \pm 12.1(n=119)$ & $114.6 \pm 12.0(n=36)$ & $115.5 \pm 12.2(n=83)$ & $p=0.720^{\ddagger}$ \\
\hline Diastolic blood pressure $(\mathrm{mmHg})$ & $70.8 \pm 8.1(n=119)$ & $68.5 \pm 7.6(n=36)$ & $71.8 \pm 8.1(n=83)$ & $p=0.046^{\ddagger *}$ \\
\hline Fasting blood glucose $(\mathrm{mg} / \mathrm{dL})$ & $92.2 \pm 7.1(n=95)$ & $92.5 \pm 8.2(n=30)$ & $92.1 \pm 6.5(n=65)$ & $p=0.779^{\dagger}$ \\
\hline Insulin $(\mu \mathrm{U} / \mathrm{mL})$ & $24.4 \pm 11.7(n=86)$ & $25.7 \pm 11.8(n=24)$ & $23.9 \pm 11.7(n=62)$ & $p=0.516^{\ddagger}$ \\
\hline HOMA Index & $5.6 \pm 2.7(n=86)$ & $5.9 \pm 2.7(n=24)$ & $5.5 \pm 2.7(n=62)$ & $p=0.441^{\ddagger}$ \\
\hline Total cholesterol $(\mathrm{mg} / \mathrm{dL})$ & $165.4 \pm 26.8(n=96)$ & $160.9 \pm 21.3(n=30)$ & $167.5 \pm 28.9(n=66)$ & $p=0.268^{\dagger}$ \\
\hline HDL cholesterol $(\mathrm{mg} / \mathrm{dL})$ & $45.4 \pm 8.7(n=96)$ & $44.1 \pm 8.9(n=30)$ & $45.9 \pm 8.6(n=66)$ & $p=0.354^{\dagger}$ \\
\hline LDL cholesterol $(\mathrm{mg} / \mathrm{dL})$ & $97.7 \pm 24.3(n=96)$ & $94.5 \pm 19.8(n=30)$ & $99.1 \pm 26.1(n=66)$ & $p=0.388^{\dagger}$ \\
\hline Triglycerides $(\mathrm{mg} / \mathrm{dL})$ & $119.2 \pm 69.9(n=96)$ & $118.6 \pm 51.9(n=30)$ & $119.4 \pm 77.1(n=66)$ & $p=0.543 \ddagger$ \\
\hline GOT $(\mathrm{U} / \mathrm{L})$ & $27.4 \pm 14.9(n=95)$ & $24.4 \pm 7.9(n=30)$ & $28.8 \pm 17.1(n=65)$ & $p=0.207^{\ddagger}$ \\
\hline GPT $(\mathrm{U} / \mathrm{L})$ & $29.2 \pm 30.5 .(n=95)$ & $21.1 \pm 14.3(n=30)$ & $33.0 \pm 35.1(n=65)$ & $p=0.0033^{\ddagger *}$ \\
\hline GGT $(\mathrm{U} / \mathrm{L})$ & $23.8 \pm 13.5(n=93)$ & $19.7 \pm 5.5(n=29)$ & $25.6 \pm 15.5(n=64)$ & $p=0.028^{\ddagger *}$ \\
\hline hs-CRP $(\mathrm{mg} / \mathrm{L})$ & $3.7 \pm 3.0(n=30)$ & $1.4 \pm 1.3(n=6)$ & $4.3 \pm 3.0(n=24)$ & $p=0.009{ }^{\ddagger *}$ \\
\hline Leptin $(\mathrm{ng} / \mathrm{mL})$ & $11.6 \pm 6.2(n=28)$ & $15.7 \pm 11.2(n=5)$ & $10.7 \pm 4.4(n=23)$ & $p=0.684^{\ddagger}$ \\
\hline
\end{tabular}

Data are presented as mean $\pm \mathrm{SD}(n=$ number $)$. Abbreviations: HOMA = homeostasis model assessment; $\mathrm{HDL}=$ high-density lipoprotein; $\mathrm{LDL}$ = low-density lipoprotein; $\mathrm{GOT}$ = glutamate oxaloacetate transaminase; $\mathrm{GPT}=$ glutamate pyruvate transaminase; GGT = gamma-glutamyl transferase; hs-CRP = high-sensitivity Creactive protein. ${ }^{\dagger} t$-test for the presence of sarcopenia, ${ }^{\ddagger}$ Mann-Whitney U-test, ${ }^{*}$ statistical significance.

\subsection{Muscle Mass and Cardiorespiratory/Muscular Fitness}

Children with sarcopenia had higher BIA fat mass $(p=0.032)$ and lower MFR $(p<0.001)$, lower physical performance $(p=0.001)$, and lower jumping distance $(p=0.041)$. Muscle mass, SMM, and SMI did not differ significantly (see Table 3).

Table 3. SMM, SMI, MFR, cardiorespiratory, and muscular fitness of the whole group and by the presence of sarcopenia.

\begin{tabular}{ccccc}
\hline Parameter & Total & Sarcopenia Absent & Sarcopenia Present & $p$-Value \\
\hline Fat mass $(\mathrm{kg})$, anthropometric & $19.8 \pm 7.0(n=119)$ & $18.2 \pm 4.9(n=36)$ & $20.5 \pm 7.7(n=83)$ & $p=0.214^{\ddagger}$ \\
\hline Fat mass $(\mathrm{kg}), \mathrm{BIA}$ & $28.1 \pm 10.6(n=119)$ & $24.5 \pm 7.7(n=36)$ & $29.6 \pm 11.4(n=83)$ & $p=0.032^{\ddagger *}$ \\
\hline Muscle mass $(\mathrm{kg}), \mathrm{BIA}$ & $23.6 \pm 7.4(n=119)$ & $24.3 \pm 5.8(n=36)$ & $23.3 \pm 7.9(n=83)$ & $p=0.163 \ddagger$ \\
\hline SMM $(\mathrm{kg})$ & $24.8 \pm 5.6(n=118)$ & $23.7 \pm 4.4(n=35)$ & $25.2 \pm 6.0(n=83)$ & $p=0.242^{\ddagger}$ \\
\hline SMI $(\%)$ & $33.3 \pm 5.2(n=118)$ & $33.1 \pm 4.5(n=35)$ & $33.4 \pm 5.5(n=83)$ & $p=0.748^{\ddagger *}$ \\
\hline SMI $\left(\mathrm{kg} / \mathrm{m}^{2}\right)$ & $9.4 \pm 1.8(n=118)$ & $9.7 \pm 1.5(n=35)$ & $9.2 \pm 1.9(n=83)$ & $p=0.074^{\ddagger}$ \\
\hline MFR & $0.89 \pm 0.22(n=119)$ & $1.04 \pm 0.23(n=36)$ & $0.82 \pm 0.18(n=83)$ & $p<0.0011^{\ddagger *}$ \\
\hline $\begin{array}{c}\text { Relative cardiorespiratory fitness } \\
\text { (watts/kg) }\end{array}$ & $1.6 \pm 0.5(n=118)$ & $1.9 \pm 0.4(n=36)$ & $1.6 \pm 0.5(n=82)$ & $p=0.001^{\dagger *}$ \\
\hline $\begin{array}{c}\text { Muscular fitness/standing long } \\
\text { jump }(\mathrm{cm})\end{array}$ & $108.8 \pm 22.9(n=84)$ & $116.2 \pm 22.4(n=27)$ & $105.3 \pm 22.5(n=57)$ & $p=0.041^{\dagger *}$ \\
\hline
\end{tabular}

Data are presented as mean $\pm \mathrm{SD}(n=$ number $)$. Abbreviations: $\mathrm{BIA}=$ bioelectric impedance analysis; $\mathrm{SMM}=$ skeletal muscle mass; SMI = skeletal muscle index; MFR $=$ muscle-to-fat ratio. ${ }^{\dagger} t$-test for the presence of sarcopenia, ‡ Mann-Whitney U-test, * statistical significance.

\subsection{Sarcopenia and MetS}

Regarding the classification of the metabolic syndrome according to the modified IDF classification [38] (see Appendix A Table A1) and the presence of sarcopenia, the Chi-squared test showed no significant difference $(p=0.747)$. 


\section{Discussion}

To our knowledge, this is one of the first studies to examine sarcopenia in overweight and obese children and adolescents and its association with selected cardiometabolic risk factors and exercise capacity. Of the participants, $69.7 \%$ were characterised as sarcopenic, which was associated with higher values for waist circumference, BMI-SDS, GGT, GPT, hs$\mathrm{CRP}$, and diastolic blood pressure, and lower cardiorespiratory and muscular fitness. There was no correlation between sarcopenia and systolic blood pressure, lipids, or fasting blood glucose, insulin levels, and HOMA index, or components of the MetS. However, already in this age group, indications of systemic inflammation, NAFLD, and blood pressure are shown.

It may be possible that the disease value would have been clearer with a larger and less homogeneous sample (all the children and adolescents were obese). So far, the occurrence of sarcopenia or sarcopenic obesity has been analysed mainly in the context of older and/or chronically ill subjects [42]. Orkin et al. showed that BIA measures of muscle and fat mass correlate strongly with magnetic resonance imaging (MRI) measures of total psoas muscle surface area (tPMSA) and fat areas in children with obesity and NAFLD. However, they did not explicitly take into account the occurrence of sarcopenia [43].

As with older persons, there is a lack of gold standard for the definition of sarcopenic obesity in children and adolescents [22,42]. We followed the cut-off values of the MFR (cut off = mean value -2 SD of the MFR of the middle fifth of BMI range) defined by McCarthy et al. using BIA muscle and fat mass [20]. Further studies using dual energy X-ray (DEXA) for body composition showed that with a lower cut-off value (cut-off value of the mean value minus 1 SD of the MFR for the third BMI quintile), the proportion of children below this value is higher [22]. Therefore, it must be critically questioned whether sarcopenic obesity is adequately represented by the ratio of muscle to fat mass. However, in addition to the MFR, other methods for determining muscle strength, mass, and power are recommended for the diagnosis of sarcopenia [16].

While DEXA serves as the gold standard for determining muscle mass, it is significantly more time consuming and expensive than BIA. Segmental BIA has proven to be an effective and practical alternative $[16,20,44]$ especially when using multi-frequency devices as in our analysis [30]. Chen et al. compared the results of BIA and DEXA in 1476 children and adolescents aged 7-17 years and showed high comparability in the determination of body fat [45]. Similar studies used the appendicular skeletal muscle mass (the sum of the skeletal muscle mass in all four extremities) to calculate muscle mass by Tanita BC-418MA single frequency $(50 \mathrm{~Hz})$ Segmental Body Composition Analyser [20].

Additionally, muscle strength in general is measured by handgrip strength [16]. Due to a lack of data on handgrip strength, we analysed the results of the standing long jump to determine muscular fitness in the lower limbs, as other studies have shown that this is a valid parameter $[46,47]$.

In older persons, muscle performance is often determined by the short physical performance battery, the 6-min walk, or the timed get-up-and-go test [16]. For our younger population, we added cardiorespiratory fitness measured in watts $/ \mathrm{kg}$.

However, taking into account the methodological approach, this cross-sectional analysis shows that sarcopenic obesity in children and adolescents increases the risk of systemic inflammation or NAFLD, diastolic blood pressure, and poorer cardiorespiratory and muscular fitness. In association with other inflammatory cytokines, adipokines and/or myokines such as IL-6 and TNF-alpha should be examined in larger collectives. However, first of all, a unique definition and assessment in this age group has to be developed. Additionally, future prospective studies should consider measuring the clinical significance of sarcopenia and sarcopenic obesity in children and adolescence. In addition to general primary prevention measures in kindergartens and schools to promote a healthy lifestyle (including the preservation of muscle mass), we recommend including parameters such as MFR in paediatric health examinations.

This study has strengths and limitations in addition to those already mentioned. One strength is the presence of factors relevant to the assessment of sarcopenic obesity 
and possible associated disorders. However, in this rather small, selected group, the pubertal status was not taken into account, because the Tanner stage was not recorded. Studies have shown that puberty can reduce the risk of elevated total cholesterol and LDL cholesterol [48]. In addition, puberty involves a physiological insulin resistance of the body, which is a central element in the development of a MetS [11]. Another limitation is the use of BIA to determine body compositions as mentioned above. A determination of the body compositions by DEXA and on this basis determined could possibly lead to more precise results [17]. For further studies, especially in the development of a uniform definition of sarcopenic obesity in this age group, the use of a DEXA is recommended.

As a main limitation, we have already pointed out the lack of a clear definition and methodical recording of sarcopenia in children and adolescents. The laboratory determination of GGT and GPT does not necessarily mean that NAFLD is present. Abdominal ultrasound examinations or even liver biopsies were not possible in our study. In addition to the determination of the MFR, simpler and more accessible methods for diagnosing sarcopenia should be implemented. One suggestion is the handgrip-to-BMI ratio defined by Steffl et al. [17].

Lower relative handgrip strength in children was associated with higher BMI and waist circumference [18]. Therefore, the authors recommended using the handgrip to BMI ratio to identify children at a risk of sarcopenic obesity [17]. The extent to which this would lead to different results remains speculative at present.

\section{Conclusions}

In summary, sarcopenia according to the used definition is present in more than two-thirds of our population of children and adolescents with overweight and obesity. In this group, sarcopenic obesity is associated with poorer cardiorespiratory and muscular fitness, elevated GGT, GPT, and hs-CRP levels, and elevated diastolic blood pressure. However, to identify the clinical value, a unique definition and methods not only based on the ration between muscle and fat mass to identify children at risk are preconditions. Subsequently, appropriate preventive and therapeutic countermeasures at an early stage have to be developed.

Author Contributions: Conceptualisation, C.S. and C.J.; methodology, C.S., C.J., N.F., G.T. and H.W.; investigation, D.F., M.K., F.H. and L.S.; resources, C.J.; data curation, C.J. and F.H.; writing-original draft preparation, C.S. and C.J.; writing-review and editing, C.S. and C.J.; project administration, C.J, D.F., M.K., F.H. and L.S. All authors have read and agreed to the published version of the manuscript.

Funding: This research received no external funding.

Institutional Review Board Statement: The study was conducted according to the guidelines of the Declaration of Helsinki and approved by the Ethics Committee Ethics of the German Sport University Cologne for the ethic request with the number 107/2014, which was updated on 17 May 2021 ('Children's Health InterventionaL Trial III—ein ambulantes, multimodales, familienbasiertes Schulungsprogamm zur Therapie von Ubergewicht und Adipositas im Kindes- und Jugendalter').

Informed Consent Statement: Informed consent was obtained from the participants' parents involved in the study.

Data Availability Statement: The data used and analysed during the current study involve sensitive patient information and indirect identifiers. As a result, the datasets are not available.

Acknowledgments: We gratefully acknowledge all CHILT III participants and their parents. We also want to thank Astrid Hofrichter for analysing the blood samples.

Conflicts of Interest: The authors declare no conflict of interest.

\section{Appendix A}

Table A1: Definitions of the metabolic syndrome, Table A2: Anthropometric data for the group of sarcopenia present in girls and boys, Table A3: Blood pressure and laboratory parameters of the group of sarcopenia present in girls and boys, Table A4: SMM, SMI, MFR, 
cardiorespiratory fitness, and standing long jump of the group of sarcopenia present in girls and boys.

Table A1. Definitions of the metabolic syndrome.

\begin{tabular}{|c|c|}
\hline Modified IDF Definition [38] for 10-16-Years Old & IDF Definition > 16 Years Old [39] \\
\hline$W C \geq 90$. percentile & $\mathrm{WC} \mathrm{m} \geq 94 \mathrm{~cm}, \mathrm{f} \geq 80 \mathrm{~cm}$ or $\mathrm{BMI} \geq 30 \mathrm{~kg} / \mathrm{m}^{2}$ \\
\hline $\mathrm{SBP} \geq 130 \mathrm{mmHg}$ or $\mathrm{DBP} \geq 85 \mathrm{mmHg}$ & $\begin{array}{c}\mathrm{SBP} \geq 130 \mathrm{mmHg} \text { or } \mathrm{DBP} \geq 85 \mathrm{mmHg} \text { or treatment of previously diagnosed } \\
\text { hypertension }\end{array}$ \\
\hline Triglycerides $\geq 150 \mathrm{mg} / \mathrm{dL}(\geq 1.7 \mathrm{mmol} / \mathrm{L})$ & Triglycerides $\geq 150 \mathrm{mg} / \mathrm{dL}$ or specific treatment for this lipid abnormality \\
\hline $\mathrm{HDL}<40 \mathrm{mg} / \mathrm{dL}(<1.03 \mathrm{mmol} / \mathrm{L})$ & $\mathrm{HDL} \mathrm{m}<40 \mathrm{mg} / \mathrm{dL}(<1.03 \mathrm{mmol} / \mathrm{L}), \mathrm{f}<50 \mathrm{mg} / \mathrm{dL}(<1.29 \mathrm{mmol} / \mathrm{L})$ \\
\hline Fasting blood glucose $\geq 100 \mathrm{mg} / \mathrm{dL}(\geq 5.6 \mathrm{mmol} / \mathrm{L})$ or DM type 2 & $\begin{array}{l}\text { Fasting blood glucose } \geq 100 \mathrm{mg} / \mathrm{dL}(\geq 5.6 \mathrm{mmol} / \mathrm{L}) \text { or } \\
\text { DM type } 2\end{array}$ \\
\hline MetS $=$ WC $\geq 90$. percentile +2 criteria & MetS $=$ WC $\mathrm{m} \geq 94 \mathrm{~cm}, \mathrm{f} \geq 80 \mathrm{~cm}$ or $\mathrm{BMI} \geq 30 \mathrm{~kg} / \mathrm{m}^{2}+2$ criteria \\
\hline
\end{tabular}

Abbreviations: $\mathrm{WC}=$ waist circumference; $\mathrm{SPB}=$ systolic blood pressure; $\mathrm{DPB}=$ diastolic blood pressure $\mathrm{HDL}=$ high-density lipoprotein; $\mathrm{DM}=$ diabetes mellitus; $\mathrm{m}=\mathrm{men} ; \mathrm{w}=$ women .

Table A2. Anthropometric data for the group of sarcopenia present in girls and boys.

\begin{tabular}{cccc}
\hline Parameter & Girls & Boys & $p$-Value \\
\hline Age $($ years $)$ & $11.6 \pm 2.5(n=25)$ & $12.4 \pm 2.2(n=58)$ & $p=0.209 \ddagger$ \\
\hline Height $(\mathrm{m})$ & $1.53 \pm 0.13(n=25)$ & $1.58 \pm 0.14(n=58)$ & $p=0.105 \ddagger$ \\
\hline Weight $(\mathrm{kg})$ & $72.1 \pm 20.8(n=25)$ & $80.7 \pm 26.2(n=58)$ & $p=0.288 \ddagger$ \\
\hline BMI $\left(\mathrm{kg} / \mathrm{m}^{2}\right)$ & $30.1 \pm 5.0(n=25)$ & $31.4 \pm 6.3(n=58)$ & $p=0.481 \ddagger$ \\
\hline BMI-SDS & $2.62 \pm 0.44(n=25)$ & $2.57 \pm 0.49(n=58)$ & $p=0.627 \ddagger$ \\
\hline Waist circumference $(\mathrm{cm})$ & $92.4 \pm 9.7(n=25)$ & $100.9 \pm 17.0(n=57)$ & $p=0.042 \ddagger *$
\end{tabular}

Data are presented as mean \pm SD $(n=$ number $)$. Abbreviations: BMI = body mass index; SDS = standard deviation score. ${ }^{\ddagger}$ Mann-Whitney U-test for girls/boys, ${ }^{*}$ statistical significance.

Table A3. Blood pressure and laboratory parameters of the group of sarcopenia present in girls and boys.

\begin{tabular}{cccc}
\hline Parameter & Girls & Boys & $p$-Value \\
\hline Systolic blood pressure $(\mathrm{mmHg})$ & $113.2 \pm 11.9(n=25)$ & $116.6 \pm 12.3(n=58)$ & $p=0.136^{\ddagger}$ \\
\hline Diastolic blood pressure $(\mathrm{mmHg})$ & $73.5 \pm 7.3(n=25)$ & $71.0 \pm 8.4(n=58)$ & $p=0.164^{\ddagger}$ \\
\hline Fasting blood glucose $(\mathrm{mg} / \mathrm{dL})$ & $89.8 \pm 5.4(n=19)$ & $93.0 \pm 6.8(n=46)$ & $p=0.079 \ddagger$ \\
\hline Insulin $(\mu \mathrm{U} / \mathrm{mL})$ & $22.1 \pm 11.0(n=17)$ & $24.5 \pm 12.1(n=45)$ & $p=0.390^{\ddagger}$ \\
\hline HOMA Index & $5.0 \pm 2.7(n=17)$ & $5.6 \pm 2.7(n=45)$ & $p=0.273^{\ddagger}$ \\
\hline Total cholesterol $(\mathrm{mg} / \mathrm{dL})$ & $171.7 \pm 27.2(n=19)$ & $165.8 \pm 29.7(n=47)$ & $p=0.332^{\ddagger}$ \\
\hline HDL cholesterol $(\mathrm{mg} / \mathrm{dL})$ & $47.6 \pm 6.3(n=19)$ & $45.3 \pm 9.4(n=47)$ & $p=0.272^{\ddagger}$ \\
\hline LDL cholesterol $(\mathrm{mg} / \mathrm{dL})$ & $102.9 \pm 23.7(n=19)$ & $97.6 \pm 27.1(n=47)$ & $p=0.506^{\ddagger}$ \\
\hline Triglycerides $(\mathrm{mg} / \mathrm{dL})$ & $109.8 \pm 52.5(n=19)$ & $123.3 \pm 85.2(n=47)$ & $p=0.745^{\ddagger}$ \\
\hline GOT $(\mathrm{U} / \mathrm{L})$ & $23.9 \pm 8.1(n=19)$ & $30.9 \pm 19.3(n=46)$ & $p=0.063^{\ddagger}$ \\
\hline GPT $(\mathrm{U} / \mathrm{L})$ & $21.5 \pm 12.4(n=19)$ & $37.7 \pm 40.1(n=46)$ & $p=0.006^{\ddagger *}$ \\
\hline GGT $(\mathrm{U} / \mathrm{L})$ & $23.4 \pm 16.2(n=18)$ & $26.5 \pm 15.4(n=46)$ & $p=0.175^{\ddagger}$ \\
\hline hs-CRP $(\mathrm{mg} / \mathrm{L})$ & $3.9 \pm 2.5(n=7)$ & $4.4 \pm 3.3(n=17)$ & $p=0.852^{\ddagger}$ \\
\hline Leptin $(\mathrm{ng} / \mathrm{mL})$ & $9.1 \pm 2.9(n=7)$ & $11.4 \pm 4.8(n=16)$ & $p=0.308^{\ddagger}$
\end{tabular}

Data are presented as mean \pm SD $(n=$ number $)$. Abbreviations: HOMA $=$ homeostasis model assessment; $\mathrm{HDL}=$ high-density lipoprotein; LDL = low-density lipoprotein; GOT = glutamate oxaloacetate transaminase; $\mathrm{GPT}=$ glutamate pyruvate transaminase; GGT = gamma-glutamyl transferase; hs-CRP $=$ high-sensitivity C-

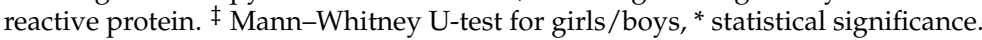


Table A4. SMM, SMI, MFR, cardiorespiratory fitness, and standing long jump of the group of sarcopenia present in girls and boys.

\begin{tabular}{cccc}
\hline Parameter & Girls & Boys & $p$-Value \\
\hline $\begin{array}{c}\text { Fat mass }(\mathrm{kg}), \\
\text { anthropometric }\end{array}$ & $18.7 \pm 6.3(n=25)$ & $21.3 \pm 8.1(n=58)$ & $p=0.258^{\ddagger}$ \\
\hline Fat mass $(\mathrm{kg}), \mathrm{BIA}$ & $28.5 \pm 9.8(n=25)$ & $30.1 \pm 12.1(n=58)$ & $p=0.770^{\ddagger}$ \\
\hline Muscle mass $(\mathrm{kg}), \mathrm{BIA}$ & $21.0 \pm 5.8(n=25)$ & $24.3 \pm 8.6(n=58)$ & $p=0.130^{\ddagger}$ \\
\hline SMM $(\mathrm{kg})$ & $20.2 \pm 3.6(n=25)$ & $27.4 \pm 5.5(n=58)$ & $p<0.001^{\ddagger *}$ \\
\hline SMI $(\%)^{1}$ & $29.0 \pm 4.1(n=25)$ & $35.3 \pm 5.0(n=58)$ & $p<0.001^{\ddagger *}$ \\
\hline SMI $\left(\mathrm{kg} / \mathrm{m}^{2}\right)$ & $8.8 \pm 1.4(n=25)$ & $9.4 \pm 2.1(n=58)$ & $p=0.202^{\ddagger}$ \\
\hline MFR & $0.76 \pm 0.11(n=25)$ & $0.85 \pm 0.19(n=58)$ & $p=0.026^{\ddagger *}$ \\
\hline $\begin{array}{c}\text { Relative cardiorespiratory } \\
\text { fitness (watts/kg) }\end{array}$ & $1.6 \pm 0.6(n=24)$ & $1.5 \pm 0.4(n=58)$ & $p=0.717^{\ddagger}$ \\
\hline $\begin{array}{c}\text { Muscular fitness/standing } \\
\text { long jump }(\mathrm{cm})\end{array}$ & $100.2 \pm 9.8(n=16)$ & $107.2 \pm 25.7(n=41)$ & $p=0.248^{\ddagger}$
\end{tabular}

Data are presented as mean \pm SD $(\mathrm{n}=$ number). Abbreviations: BIA = bioelectric impedance analysis; SMM = skeletal muscle mass; SMI = skeletal muscle index; MFR = muscle-to-fat ratio. $\ddagger$ Mann-Whitney U-test girls/boys, * statistical significance, $^{1}$ Janssen et al. [33].

\section{References}

1. Schienkiewitz, A.; Brettschneider, A.-K.; Damerow, S.; Schaffrath Rosario, A. Übergewicht und Adipositas im Kindes- und Jugendalter in Deutschland-Querschnittergebnisse aus KiGGS Welle 2 und Trends. J. Health Monit. 2018, 3, 16-23. [CrossRef]

2. Abarca-Gómez, L.; Abdeen, Z.A.; Hamid, Z.A.; Abu-Rmeileh, N.M.; Acosta-Cazares, B.; Acuin, C.; Adams, R.J.; Aekplakorn, W.; Afsana, K.; Aguilar-Salinas, C.A.; et al. Worldwide trends in body-mass index, underweight, overweight, and obesity from 1975 to 2016: A pooled analysis of 2416 population-based measurement studies in 128.9 million children, adolescents, and adults. Lancet 2017, 390, 2627-2642. [CrossRef]

3. Jia, P.; Zhang, L.; Yu, W.; Yu, B.; Liu, M.; Zhang, D.; Yang, S. Impact of COVID-19 lockdown on activity patterns and weight status among youths in China: The COVID-19 Impact on Lifestyle Change Survey (COINLICS). Int. J. Obes. 2021, 45, 695-699. [CrossRef] [PubMed]

4. $\quad$ Singh, A.S.; Mulder, C.; Twisk, J.W.R.; van Mechelen, W.; Chinapaw, M.J.M. Tracking of childhood overweight into adulthood: A systematic review of the literature. Obes. Rev. 2008, 9, 474-488. [CrossRef] [PubMed]

5. Roth, C.; Lakomek, M.; Müller, H.; Harz, K.J. Adipositas im Kindesalter: Ursachen und Therapiemöglichkeiten. Monatsschr. Kinderheilkd. 2002, 150, 329-336. [CrossRef]

6. Knop, C.; Reinehr, T. Adipositas im Kindes- und Jugendalter. Aktuelle ErnäHrungsmedizin 2015, 40, 109-122. [CrossRef]

7. Friedemann, C.; Heneghan, C.; Mahtani, K.; Thompson, M.; Perera, R.; Ward, A.M. Cardiovascular disease risk in healthy children and its association with body mass index: Systematic review and meta-analysis. BMJ 2012, 345, e4759. [CrossRef]

8. Llewellyn, A.; Simmonds, M.; Owen, C.G.; Woolacott, N. Childhood obesity as a predictor of morbidity in adulthood: A systematic review and meta-analysis. Obes. Rev. 2016, 17, 56-67. [CrossRef]

9. Ebbeling, C.B.; Pawlak, D.B.; Ludwig, D.S. Childhood obesity: Public-health crisis, common sense cure. Lancet 2002, 360, 473-482. [CrossRef]

10. Reinehr, T.; de Sousa, G.; Toschke, A.M.; Andler, W. Comparison of metabolic syndrome prevalence using eight different definitions: A critical approach. Arch. Dis. Child. 2007, 92, 1067-1072. [CrossRef]

11. Wabitsch, M.; Moss, A.; Denzer, C.; Fischer-Posovsky, P. Das metabolische Syndrom. Monatsschr. Kinderheilkd. 2012, 160, 277-292. [CrossRef]

12. Hanefeld, M.; Pistrosch, F. Metabolisches Syndrom und Insulinresistenz. Gastroenterologe 2017, 12, 300-304. [CrossRef]

13. Park, B.S.; Yoon, J.S. Relative skeletal muscle mass is associated with development of metabolic syndrome. Diabetes Metab. J. 2013, 37, 458-464. [CrossRef]

14. Cauley, J.A. An Overview of Sarcopenic Obesity. J. Clin. Densitom. 2015, 18, 499-505. [CrossRef] [PubMed]

15. Baumgartner, R.N. Body composition in healthy aging. Ann. N. Y. Acad. Sci. 2000, 904, 437-448. [CrossRef] [PubMed]

16. Cruz-Jentoft, A.J.; Baeyens, J.P.; Bauer, J.M.; Boirie, Y.; Cederholm, T.; Landi, F.; Martin, F.C.; Michel, J.-P.; Rolland, Y.; Schneider, S.M.; et al. Sarcopenia: European consensus on definition and diagnosis: Report of the European Working Group on Sarcopenia in Older People. Age Ageing 2010, 39, 412-423. [CrossRef]

17. Steffl, M.; Chrudimsky, J.; Tufano, J.J. Using relative handgrip strength to identify children at risk of sarcopenic obesity. PLoS ONE 2017, 12, e0177006. [CrossRef] 
18. Palacio-Agüero, A.; Díaz-Torrente, X.; Quintiliano Scarpelli Dourado, D. Relative handgrip strength, nutritional status and abdominal obesity in Chilean adolescents. PLOS ONE 2020, 15, e0234316. [CrossRef]

19. Kim, T.N.; Park, M.S.; Lim, K.I.; Yang, S.J.; Yoo, H.J.; Kang, H.J.; Song, W.; Seo, J.A.; Kim, S.G.; Kim, N.H.; et al. Skeletal muscle mass to visceral fat area ratio is associated with metabolic syndrome and arterial stiffness: The Korean Sarcopenic Obesity Study (KSOS). Diabetes Res. Clin. Pract. 2011, 93, 285-291. [CrossRef] [PubMed]

20. McCarthy, H.D.; Samani-Radia, D.; Jebb, S.A.; Prentice, A.M. Skeletal muscle mass reference curves for children and adolescents. Pediatr. Obes. 2014, 9, 249-259. [CrossRef]

21. Lier, L.M.; Breuer, C.; Ferrari, N.; Friesen, D.; Maisonave, F.; Schmidt, N.; Graf, C. Individual Physical Activity Behaviour and Group Composition as Determinants of the Effectiveness of a Childhood Obesity Intervention Program. Obes. Facts 2021, 14, 100-107. [CrossRef] [PubMed]

22. Kim, K.; Hong, S.; Kim, E.Y. Reference Values of Skeletal Muscle Mass for Korean Children and Adolescents Using Data from the Korean National Health and Nutrition Examination Survey 2009-2011. PLoS ONE 2016, 11, e0153383. [CrossRef] [PubMed]

23. Lier, L.M.; Breuer, C.; Ferrari, N.; Friesen, D.; Maisonave, F.; Schmidt, N.; Graf, C. Cost-effectiveness of a family-based multicomponent outpatient intervention program for children with obesity in Germany. Public Health 2020, 186, 185-192. [CrossRef] [PubMed]

24. Kromeyer-Hauschild, K.; Wabitsch, M.; Kunze, D.; Geller, F.; Geiß, H.C.; Hesse, V.; von Hippel, A.; Jaeger, U.; Johnsen, D.; Korte, W.; et al. Perzentile für den Body-mass-Index für das Kindes- und Jugendalter unter Heranziehung verschiedener deutscher Stichproben. Monatsschr. Kinderheilkd. 2001, 149, 807-818. [CrossRef]

25. Wabitsch, M.; Kunze, D. Konsensbasierte AGA S2-Leitlinie zur Diagnostik, Therapie und Prävention von Übergewicht und Adipositas im Kindes- und Jugendalter: Version 15.10.2015. Available online: https://www.awmf.org/uploads/tx_szleitlinien/ 050-0021_S3_Therapie-Praevention-Adipositas-Kinder-Jugendliche_2019-11.pdf (accessed on 21 November 2021).

26. Lohman, T.G.; Roche, A.F.; Martorel, R. Anthropometric Standardization Reference Manual; Human Kinetics Books: Champaign, IL, USA, 1988; ISBN 978-087-322-121-4.

27. Slaughter, M.H.; Lohman, T.G.; Boileau, R.A.; Horswill, C.A.; Stillman, R.J.; van Loan, M.D.; Bemben, D.A. Skinfold equations for estimation of body fatness in children and youth. Hum. Biol. 1988, 60, 709-723. [PubMed]

28. Chan, D.F.Y.; Li, A.M.; So, H.K.; Yin, J.; Nelson, E.A.S. New Skinfold-thickness Equation for Predicting Percentage Body Fat in Chinese Obese Children. Hong Kong J. Paediatr. 2009, 14, 96-102.

29. Rodríguez, G.; Moreno, L.A.; Blay, M.G.; Blay, V.A.; Fleta, J.; Sarría, A.; Bueno, M. Body fat measurement in adolescents: Comparison of skinfold thickness equations with dual-energy X-ray absorptiometry. Eur. J. Clin. Nutr. 2005, 59, 1158-1166. [CrossRef]

30. Data Input. Nutriguard-MS Gebrauchsanleitung: Version 2.0. 2019. Available online: https://www.data-input.de/media/pdf_ deutsch_2018/Gebrauchsanleitung_Nutriguard\%20MS_2019.pdf (accessed on 29 November 2021).

31. Data Input. Nutri Plus Gebrauchsanleitung: Software zur Bestimmung von Körperzusammensetzung und Ernährungszustand aus BIA-Messungen. Available online: https://data-input.de/media/pdf_deutsch_2018/Data_Input_NutriPlus_ Gebrauchsanleitung_DE.pdf (accessed on 21 November 2021).

32. Janssen, I.; Heymsfield, S.B.; Baumgartner, R.N.; Ross, R. Estimation of skeletal muscle mass by bioelectrical impedance analysis. J. Appl. Physiol. 2000, 89, 465-471. [CrossRef]

33. Janssen, I.; Heymsfield, S.B.; Ross, R. Low relative skeletal muscle mass (sarcopenia) in older persons is associated with functional impairment and physical disability. J. Am. Geriatr. Soc. 2002, 50, 889-896. [CrossRef]

34. Hager, A.; Wühl, E.; Bönner, G.; Hulpke-Wette, M.; Läer, S.; Weil, J. S2k Leitlinie Pädiatrische Kardiologie, Pädiatrische Nephrologie und Pädiatrie: Arterielle Hypertonie. Available online: https:/ /www.dgpk.org/fileadmin/user_upload/Leitlinien/ LL_Arterielle_Hypertonie.pdf (accessed on 21 November 2021).

35. Nauck, M.; Warnick, G.R.; Rifai, N. Methods for Measurement of LDL-Cholesterol: A Critical Assessment of Direct Measurement by Homogeneous Assays versus Calculation. Clin. Chem. 2002, 48, 236-254. [CrossRef]

36. Landwehr, C. Zusammenhang zwischen dem Mütterlichen Lebensstil, Ausgewählten Gesundheits- und Laborparametern Sowie dem Einfluss auf die Frühkindliche Entwicklung: Die "MAMA"-Studie. Ph.D. Thesis, Deutsche Sporthochschule Köln, Cologne, Germany, 2017.

37. Matthews, D.R.; Hosker, J.R.; Rudenski, A.S.; Naylor, B.A.; Treacher, D.F.; Turner, R.C. Homeostasis model assessment: Insulin resistance and $\beta$-cell function from fasting plasma glucose and insulin concentrations in man. Diabetologia 1985, 28, 412-419. [CrossRef]

38. Zimmet, P.; Alberti, K.G.M.M.; Kaufman, F.; Tajima, N.; Silink, M.; Arslanian, S.; Wong, G.; Bennett, P.; Shaw, J.; Caprio, S. The metabolic syndrome in children and adolescents-An IDF consensus report. Pediatr. Diabetes 2007, 8, 299-306. [CrossRef]

39. Zimmet, P.; Magliano, D.; Matsuzawa, Y.; Alberti, G.; Shaw, J. The metabolic syndrome: A global public health problem and a new definition. J. Atheroscler. Thromb. 2005, 12, 295-300. [CrossRef] [PubMed]

40. Windhaber, J.; Schober, P.H. Leistungsmedizinische Ergometrie im Kindes- und Jugendalter. Monatsschr. Kinderheilkd. 2014, 162, 216-221. [CrossRef]

41. Dordel, S.; Koch, B. Basistests zur Erfassung der Motorischen Leistungsfähigkeit von Kindern und Jugendlichen-Dordel-KochTest DKT Fitnessolympiade. Available online: https:/ / fitnessolympiade.de/pdfs/manual-dordel-koch-test.pdf (accessed on 21 November 2021). 
42. Batsis, J.A.; Barre, L.K.; Mackenzie, T.A.; Pratt, S.I.; Lopez-Jimenez, F.; Bartels, S.J. Variation in the Prevalence of Sarcopenia and Sarcopenic Obesity in Older Adults Associated with Different Research Definitions: Dual-Energy X-Ray Absorptiometry Data form the National Health and Nutrition Examination Survey 1999-2004. J. Am. Geriatr. Soc. 2013, 61, 974-980. [CrossRef]

43. Orkin, S.; Yodoshi, T.; Romantic, E.; Hitchcock, K.; Arce-Clachar, A.C.; Bramlage, K.; Sun, Q.; Fei, L.; Xanthakos, S.A.; Trout, A.T.; et al. Body composition measured by bioelectrical impedance analysis is a viable alternative to magnetic resonance imaging in children with nonalcoholic fatty liver disease. JPEN J. Parenter. Enter. Nutr. 2021, Online ahead of print. [CrossRef]

44. Fuller, N.J.; Fewtrell, M.S.; Dewit, O.; Elia, M.; Wells, J.C.K. Segmental bioelectrical impedance analysis in children aged 8-12 y: 2. The assessment of regional body composition and muscle mass. Int. J. Obes. 2002, 26, 692-700. [CrossRef]

45. Chen, M.; Liu, J.; Ma, Y.; Li, Y.; Gao, D.; Chen, L.; Ma, T.; Dong, Y.; Ma, J. Association between Body Fat and Elevated Blood Pressure among Children and Adolescents Aged 7-17 Years: Using Dual-Energy X-ray Absorptiometry (DEXA) and Bioelectrical Impedance Analysis (BIA) from a Cross-Sectional Study in China. Int. J. Environ. Res. Public Health 2021, 18, 9254. [CrossRef] [PubMed]

46. Ramírez-Vélez, R.; Rodrigues-Bezerra, D.; Correa-Bautista, J.E.; Izquierdo, M.; Lobelo, F. Reliability of Health-Related Physical Fitness Tests among Colombian Children and Adolescents: The FUPRECOL Study. PLoS ONE 2015, 10, e0140875. [CrossRef]

47. Ruiz, J.R.; Castro-Piñero, J.; España-Romero, V.; Artero, E.G.; Ortega, F.B.; Cuenca, M.M.; Jimenez-Pavón, D.; Chillón, P.; GirelaRejón, M.J.; Mora, J.; et al. Field-based fitness assessment in young people: The ALPHA health-related fitness test battery for children and adolescents. Br. J. Sports Med. 2011, 45, 518-524. [CrossRef] [PubMed]

48. I'Allemand, D.; Wiegand, S.; Reinehr, T.; Müller, J.; Wabitsch, M.; Widhalm, K.; Holl, R. Cardiovascular risk in 26,008 European overweight children as established by a multicenter database. Obesity 2008, 16, 1672-1679. [CrossRef] [PubMed] 